\title{
INTERANNUAL VARIABILITY OF NDVI AND SPECIES RICHNESS IN KENYA
}

\author{
Boniface O. OINDO, Andrew K. SKIDMORE and Rolf A. de BY \\ International Institute for Aerospace Survey and Earth Sciences, \\ P.O. Box 6, 7500 AA Enschede, The Netherlands. \\ Oluoch@,itc.nl, Skidmore@,itc.nl, deby@itc.nl
}

KEYWORDS: Interannual AVHRR-NDVI, spatial scale, birds, mammals, plants, species richness, Kenya

\begin{abstract}
A central task in community ecology is to determine biophysical controls of species richness patterns. Most multivariate models relating environmental characteristics to species richness were developed with sparse point sampling from meteorological stations. However, satellite remote sensing provides an alternative, and in some ways potentially superior, means of estimating appropriate environmental factors and thereby improving predictions of species richness. The frequently used surrogate measures for species richness patterns are net primary productivity (NPP) and actual evapotranspiration (AET). Local spatial variability of NPP and AET, which indicates spatial heterogeneity, is hypothesized as another influence on species richness. The Advanced Very High Resolution Radiometer (AVHRR) derived Normalized Difference Vegetation Index (NDVI) has been shown to be related to NPP and AET in many vegetation types. We examined the relationship between interannual NDVI parameters and species richness of vascular plants, large mammals and birds. Statistical analyses revealed that at small spatial scales $(10 \times 10 \mathrm{~km})$ higher average NDVI results in lower species richness of mammals and plants, whereas standard deviation of maximum NDVI and coefficient of variation correlated positively with species richness. Conversely, at large spatial scales $(55 \mathrm{x} 55 \mathrm{~km})$ bird species richness increases as average NDVI increases, whereas higher standard deviation and coefficient of variation result in lower species richness. Thus, NDVI parameters appear to represent environmental factors influencing species richness. In other words, by utilizing remote sensing, our understanding of the spatial variability of species richness has been improved.
\end{abstract}

\section{INTRODUCTION}

Patterns of species diversity have long been of interest to biogeographers and ecologist, but explanation of the geographic variation inherent in these patterns remains a major unresolved scientific issue (Brown 1988). This interest has been recently renewed with the current sharp increase of species extinctions, as habitats are becoming more fragmented and degraded worldwide (Walker et al. 1992). Explanations of the distribution of species richness have included spatial heterogeneity, productivity, interactions among species, and dynamic processes-both evolutionary processes and disturbance regimes (Diamond 1988). The heterogeneity hypothesis states that increasing spatial heterogeneity, due to its effects on species distribution, should in general cause higher species richness (Walker et al. 1992). Therefore, at small spatial scales $(10 \times 10 \mathrm{~km})$ the interannual variability of normalized difference vegetation index (NDVI) values, as for example by the standard deviation of maximum NDVI, may be an index heterogeneity of habitats. A higher variability in NDVI should have a positive relationship with species richness of mammals and plants.

Long periods of time with a stable, predictable environment may allow high species diversity because populations would be stable and extinction rates due to population fluctuations would be low (Sanders and Hessler 1969). Moreover, stable environments permits specialization and equilibrium coexistence due to resource partitioning (Currie 1991). However, there are numerous examples of low diversity communities in stable environments (Hart et al., 1989). On the other hand, communities with high diversity are often found in environments that seem to be severe, unpredictable, or unstable (Whittaker and Niering 1965). Theoretically, NDVI can be considered as a climatic recorder, and in the tropics, mainly a rainfall recorder (Richard and Poccard 1998). It has been shown that NDVI is highly sensitive to an extended rainfall anomaly (Henricksen 1986). Thus NDVI can be used as a good proxy for the study of interannual climate variability (Richard and Poccard 1998). Interannual variability in vegetation takes place as a result of climatic variability and its effects on germination and growth (Hobbs 1990). Thus large variations in vegetation composition and growth are seen in arid and semiarid areas where rainfall is sporadic and the response of vegetation to such rainfall is rapid (Griffin and Friedel 1985). 
Hence the vegetation index time series give us a possibility to assess the climate variability over the season and over the years. Therefore, at large spatial scales $(55 \times 55 \mathrm{~km})$ the interannual variability of NDVI values, as calculated for example by the standard deviation of maximum NDVI, may indicate unstable and unpredictable environments. Consequently, high values of standard deviation of maximum NDVI and coefficient of variation should have a negative relationship with bird species richness.

The productivity hypothesis of species richness states that areas of higher net primary productivity (NPP) will tend to have greater numbers of species (Walker et al. 1992). With higher NPP, according to the hypothesis, organisms can divide resources more finely among a wider variety of species while maintaining adequately large populations so that risk of extinction is reduced (Connell and Orias 1964). However, researchers have shown that higher productivity can be either negatively or positively correlated with species richness. In fact, in many systems a unimodal pattern is found, with highest species richness at intermediate levels of productivity; above the point of central tendency species richness decreases as productivity increases, while below the point of central tendency species richness increases as productivity increases (Grime 1979). A number of explanations of this apparent paradox have appeared (Rosenzweig and Abramsky 1993), but no single theory has been accepted by ecologists.

NPP is a difficult variable to measure directly, especially at landscape or regional scales. Consequently, in regional biodiversity studies, NPP is typically derived from climatic data collected at a few scattered sampling points, which are used to characterize NPP over a large region (Currie 1991). If a strong relationship can be shown between remotely sensed data and NPP, then more complete mapping and monitoring of NPP of terrestrial vegetation may be possible (Walker et al. 1992). Normalized difference vegetation index (NDVI) has been related to NPP at broad spatial scales (Box et al. 1989; Prince 1991). The chain of relationship from NDVI to NPP and NPP to species richness provides strong evidence that NDVI is related to species richness.

In this paper, we assess the extent to which interannual AVHRR-NDVI data can be used to predict the species richness of vascular plants, large mammals and birds in Kenya. We investigated the relationships between plant as well as mammal species richness and interannually integrated NDVI parameters (viz. average, standard deviation and coefficient of variation) at spatial scale $(10 \times 10 \mathrm{~km})$ which matches the scale of data acquisition. In contrast, the relation between bird species richness and NDVI parameters was investigated at a quarter-degree scale $(55 \mathrm{x} 55 \mathrm{~km})$, that corresponds to the scale of the distribution maps in the bird's atlas of Kenya (Lewis and Pomeroy 1989).

\section{METHODS}

\subsection{Study area and species data}

Kenya is situated between latitudes $5^{\circ} 40^{\prime}$ north and $4^{\circ} 4^{\prime}$ south and between longitudes $33^{\circ} 50^{\prime}$ and $41^{\circ} 45^{\prime}$ east. With its diverse ecological communities, Kenya is a challenging yet promising location to observe whether a significant relationship exists between AVHRR-NDVI and species richness of plants, birds and mammals. The country is challenging because of its diverse landforms ranging from coastal plains to savanna grasslands to highland.

Both mammal species (body mass greater than 4kg) and plant species data for the years 1982 to 1993 were obtained from Department of Resource Surveys and Remote Sensing (DRSRS), Ministry of Environment, Kenya. The systematic reconnaissance flight methodology for animal census used by DRSRS is fully described by Norton- Griffiths (1978). The animal census data were at spatial resolution of $10 \times 10 \mathrm{~km}$. A clustered random sampling was used to collect plant species data (McIntyre 1978). Cluster points were randomly generated. Samples of plants species were taken in ten different sites within a distance of two kilometers from the main cluster. Since each cluster points were ten kilometers apart, the plant species data were recorded at a $10 \times 10 \mathrm{~km}$ resolution.

In the case of birds, the distribution maps for 871 breeding species of the 1065 species including migrants (mostly northern winter visitors) of Kenyan birds presented in Lewis and Pomeroy (1989) were photocopied, scanned in 256 gray scales and saved as Tagged image file format (Tiff). An algorithm was developed for extracting the mapping symbols for the following status of birds from the scanned tiff maps. (1) Confirmed breeding after 1/1/1970, (2) Present and probably breeding after 1/1/1970, (3) Records after 1/1/1970 (but no confirmation of breeding). The algorithm rectified the images to obtain standard northing on each. For this, it identified location of two pixel patterns that appear in all images and computed from their positions the orientation and position of the map. 
Finally, the algorithm translated, rotated and resampled the image to obtain a rectified image (all same origin and same northing). For each status of birds, the maps use a specific pattern (pattern 1 to 3 ). After rectification, the position of each block $(55 \times 55 \mathrm{~km})$ was known approximately. For each block position, the algorithm computed a slightly wider buffer and then, tried to find the best match for all 3 patterns. For some block positions, we found that lake and country boundaries obscured the recognition of patterns. We corrected for this at specific block positions by cross-checking of patterns against the maps in the bird atlas. We also looked at trends in histograms per pattern that helped to identify problems where the algorithm erroneously identified patterns.

\subsection{NOAA-AVHRR NDVI data}

The normalized difference vegetation index (NDVI) data were obtained from the United States Agency for International Development (USAID) Famine Early Warning System (FEWS) database for Kenya, for the years 1982 to 1993. The Global Inventory Monitoring and Modeling Studies (GIMMS) at the National Aeronautics and Space Administration (NASA) processed the data. The spatial resolution of the NDVI data is approximately $7.6 \mathrm{~km}$. The vegetation absorbs a great part of incoming radiation in the visible portion of the spectrum, and reaches maximum reflectance in the near infrared channel (Tucker and Sellers 1986). NDVI is computed as the normalized ratio of the difference between the near infrared (NIR) and visible (red) channels (NIR - Red)/ (NIR + Red) from surface reflectance obtained from National Oceanic Atmospheric Administration (NOAA) Advanced Very High Resolution Radiometer (AVHRR). This ratio yields a measure of photosynthetic capacity such that the higher the value of the ratio, the more photosynthetically active the cover type (Sellers 1985). The maximum-value composite procedure requires that a series of multitemporal georeferenced satellite data be processed into NDVI images. On a pixel-by-pixel basis, each NDVI value is examined, and only the highest value is retained for each pixel location (Holben 1986).

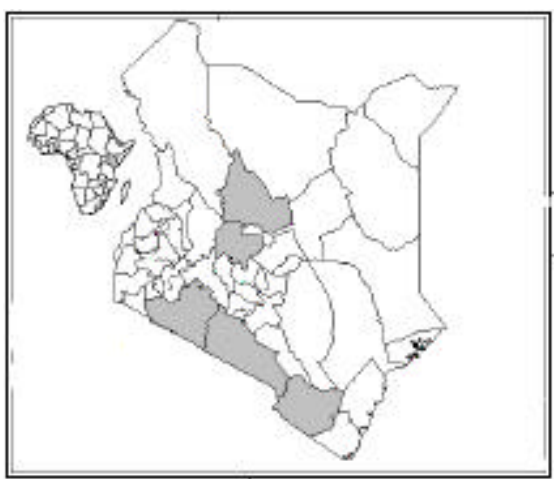

Figure 1. Location of Kenya and study districts. The analysis for mammal species was focussed on nine districts shaded light gray, namely, Baringo, Laikipia, Samburu, Narok, Kajiado, Taita Taveta, Kwale, Kilifi and Lamu. Dark gray districts are Nyeri and Nyandarua (Mt. Kenya- Aberdare region), the study areas for plant species. The study area for bird species richness covered the whole country.

The spectral response of vegetated areas presents a complex mixture of vegetation, soil brightness, environmental effects, shadow, soil color and moisture. Hence, the effect of soil brightness exerts considerable influence on the computation of vegetation indices (Bannari et al. 1995). The soil background reflectance usually affects low and intermediate NDVI values more than high NDVI values because the increased vegetation cover tends to mask the soil (Huete et al. 1985). However, the impact of soil reflectance was assumed to be minimal because time series data were analyzed for the same pixel area.

\subsection{Analysis of the data}

The NDVI time series (1982-1993) images of maximum and average NDVI (36 dekads each) were downloaded from the ADDS (1999) website (http://edcsnw4.cr.usgs.gov/bin/staform/a=ndvi/b=ke, $24^{\text {th }}$ Febraury 2000). A composite image of average NDVI (figure 2a) was created from integrated 36 dekads average NDVI images, whereas standard deviation of maximum NDVI composite image (figure $2 b$ ) was generated from 36 dekads maximum NDVI image list. The calculation of bird species richness was based on combination of the status of birds recorded since 1970 (Lewis and Pomeroy 1989), namely, confirmed breeding after $1 / 1 / 1970$, present and probable breeding after $1 / 1 / 1970$ and records after $1 / 1 / 1970$ (but no confirmation of breeding).

The number of bird species present was counted in 55 x $55 \mathrm{~km}$ quadrats to give a value for total species richness in each quadrat for the whole country. On the other hand, the number of mammal species present was counted in $10 \mathrm{x} 10 \mathrm{~km}$ quadrats to give a value for total species richness in each quadrat for the districts, Baringo, Laikipia, Samburu, Narok, Kajiado, Taita Taveta, Kwale, Kilifi and Lamu. The number of vascular plant species was also counted in $10 \mathrm{x} 10 \mathrm{~km}$ quadrats to give a value for total species richness in each quadrat for Nyeri and Nyandarua districts (Aberdares- Mt. Kenya region). 
Interannually integrated NDVI parameters (viz. average and standard deviation) were computed for every $10 \mathrm{x} 10 \mathrm{~km}$ quadrats as well as $55 \times 55 \mathrm{~km}$ quadrats. Additionally, the coefficient of variation, which indicates relative variability, was calculated for every quadrat by dividing the standard deviation with the average NDVI, expressed as a percentage. The coordinates of the quadrats containing species richness were conformed to the same geographic coordinate system as the quadrats representing NDVI parameters. Subsequently, Pearson Product- Moment correlation between species richness and interannually integrated NDVI parameter was calculated. Regression lines between the dependent variables (species richness) and the independent variables, interannually integrated NDVI parameters were calculated, as well as $95 \%$ confidence interval.

\section{RESULTS}

The results show (figure $2 \mathrm{a}$ and $\mathrm{b}$ ) that the interannually integrated NDVI parameters have distinct spatial patterns in Kenya. Predictably, the semi- humid to humid zones such as the lake Victoria region, central highlands and the coastal strip have the highest average NDVI. High values of standard deviation of maximum NDVI (figure 2b) occur in arid and semi-arid zones where large environmental gradients are present within a region, as for example from northeast to southeast part of Kenya (excluding the coastal strip). Very arid areas (e.g. northwest around Lake Turkana) exhibit low values, consistent with low average NDVI values.

Correlations varied strongly according to NDVI parameters and species. Table 1 shows that higher average NDVI results in lower species richness of plants and mammals but higher species richness of birds. In contrast, both mammal and plant species richness increase as the standard deviation of maximum NDVI and coefficient of variation increase. In contrast, bird species richness decreases with the increase of the standard deviation of maximum NDVI and coefficient of variation. In order to validate the estimates, the standard errors of the correlation coefficient between variables were estimated by bootstrap standard deviation (Efron and Tibshirani 1998). A bootstrap of 2500 random samples was drawn with replacement from the sample points of each nine districts as well as the whole country (birds). Table 1 shows that the bootstrap samples standard deviations are nearly as good as the standard errors of correlation estimates, indicating that the bootstrap replications are good estimate of the population standard error in all cases. Figure 3a-d show scatterplots of points and least-squares fit for the relationships between average NDVI and species richness of birds, mammals and plants.

Table 1. The coefficient of correlation ( $\mathrm{r}$ ) between species richness and interannually integrated NDVI parameters: Average NDVI (ANDVI), Standard deviation of maximum NDVI (SD) and Coefficient of variation (CV). SE stands for standard errors while BSD for bootstrap standard deviations. Analyses for mammal species were performed in each district as well as 9 districts (Baringo, Laikipia, Samburu, Narok, Kajiado, Taita Taveta, Kwale, Kilifi and Lamu) analyzed concurrently. Analysis for plant species focussed on Nyeri and Nyandarua (Nyeri-Nyand) districts, while bird species richness analysis covered the whole country

\begin{tabular}{lcccccccccl}
\hline District & $\begin{array}{c}\text { ANDVI } \\
\mathrm{r}\end{array}$ & $\mathrm{SE}$ & $\mathrm{BSD}$ & $\begin{array}{c}\text { SD } \\
\mathrm{r}\end{array}$ & SE & BSD & CV & SE & BSD & $\mathrm{n}$ \\
\hline Baringo & -0.546 & 3.252 & 2.700 & 0.662 & 18.92 & 19.49 & 0.733 & 0.035 & 0.041 & 51 \\
Kajiado & -0.212 & 3.137 & 2.797 & 0.346 & 14.34 & 11.93 & 0.345 & 0.025 & 0.023 & 195 \\
Kilifi & -0.667 & 5.826 & 4.908 & 0.530 & 32.28 & 28.66 & 0.708 & 0.044 & 0.041 & 40 \\
Kwale & -0.700 & 10.28 & 8.277 & 0.828 & 30.03 & 28.08 & 0.824 & 0.077 & 0.080 & 24 \\
Laikipia & -0.631 & 8.706 & 7.216 & 0.023 & 57.96 & 66.73 & 0.340 & 0.135 & 0.149 & 82 \\
Lamu & -0.569 & 5.979 & 5.506 & 0.475 & 54.51 & 41.60 & 0.553 & 0.173 & 0.126 & 48 \\
Narok & -0.482 & 4.479 & 3.582 & 0.577 & 22.92 & 22.74 & 0.568 & 0.066 & 0.066 & 113 \\
Samburu & -0.326 & 2.571 & 2.133 & 0.712 & 9.107 & 8.150 & 0.714 & 0.015 & 0.014 & 127 \\
Taita Taveta & -0.426 & 3.238 & 2.938 & 0.658 & 13.32 & 10.90 & 0.602 & 0.024 & 0.022 & 113 \\
Nyeri-Nyand & -0.849 & 29.13 & 27.36 & 0.888 & 69.03 & 64.43 & 0.938 & 0.170 & 0.221 & 20 \\
All-districts & -0.070 & 1.517 & 1.444 & 0.339 & 5.996 & 5.532 & 0.239 & 0.013 & 0.011 & 793 \\
Whole country & 0.633 & 64.72 & 59.07 & -0.289 & 458.8 & 429.5 & -0.578 & 0.674 & 0.563 & 184 \\
\hline
\end{tabular}




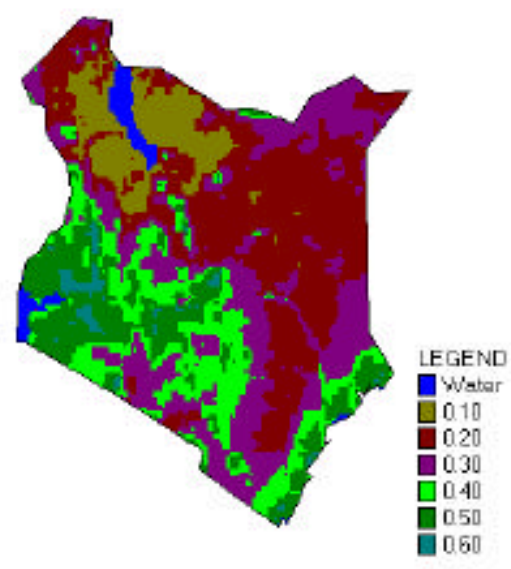

(a)

Figure 2. Spatial distribution of interannually integrated NDVI parameters of Kenya 1982-1993: (a) Composite image of average NDVI, (b) Composite image of standard deviation of maximum NDVI.

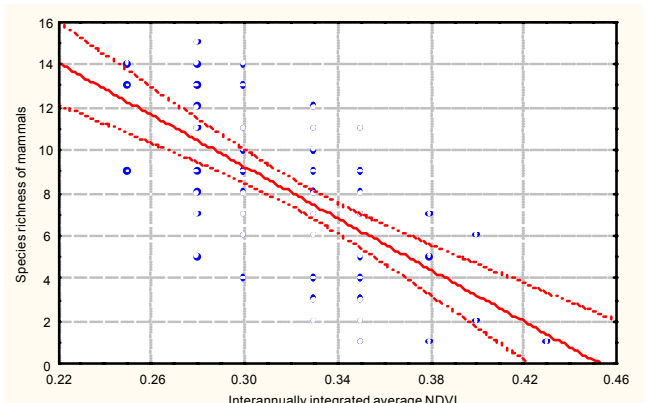

(a)

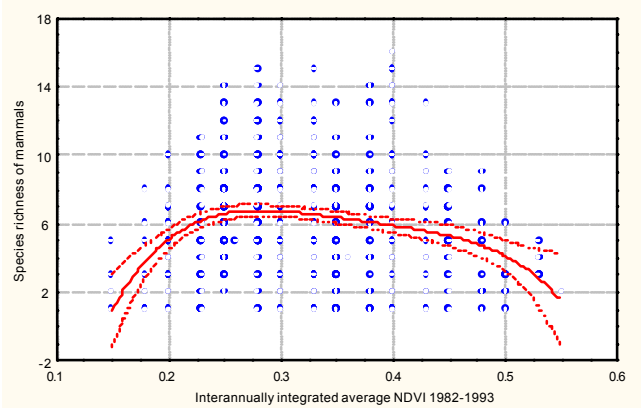

(c)

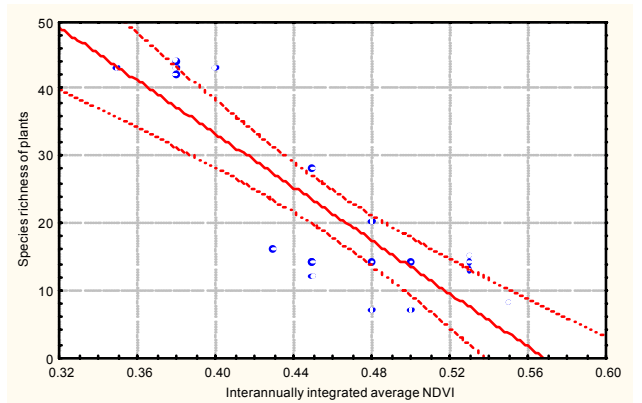

(b)

(d)

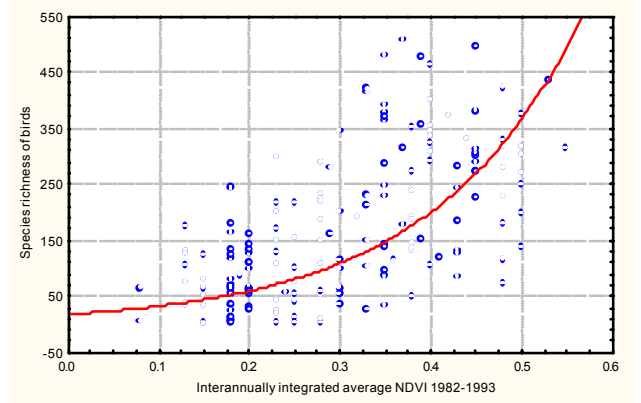

Figure 3. Scatterplots of relation between interannually integrated average NDVI and species richness of birds, mammals and plants. (a) Average NDVI versus mammal species richness in Laikipia district. (b) Average NDVI versus plant species richness in Aberdare-Mt. Kenya region. (c) Average NDVI versus mammal species richness in all nine districts (see table 1) analyzed concurrently. (d) Average NDVI versus bird species richness in the whole country.

\section{DISCUSSION}

The integrated vegetation index is representative of rate of photosynthetic plant activity, its integration over time should tell us more about the productive history of the plant, and by inference, about production (Malingreau 1989). For a number of districts in Kenya, the average NDVI, which is positively related to net primary productivity (NPP) (Box et al.1989), is negatively correlated with species richness of mammals (table 1). Figures $3 a$ and c provide evidence for the hypothesis that higher productivity (i.e. increasing average NDVI) depresses tropical mammal species richness at a landscape scale. The results support the findings of Rosenzweig and Abramsky (1993). 
The humped curve of diversity in relation to productivity has been reported for tropical mammals (Rosenzweig and Abramsky 1993). However, the increase phase may be obscured due to few sample points (figure $3 \mathrm{a}$ ), because when the districts were concurrently analyzed, a hump-shaped pattern can be noted (figure $3 \mathrm{c}$ ).

Why do maximum levels of species richness of mammals occur at intermediate levels of productivity? One possibility is that under conditions of low primary productivity in natural ecosystems, there is not much habitat or resource heterogeneity; the landscape is uniformly barren. As productivity rises, the average variety of micronutrient combinations in fertile soils increases (Rosenzweig and Abramsky 1993). This leads to a more diverse community of plants that can support a greater number of herbivore species (Begon et al. 1990). But go beyond a certain point on the productivity gradient and the habitat heterogeneity that support mammalian diversity declines (Rosenzweig and Abramsky 1993). This leads to increased production of woody species, which in turn reduces the primary production of grass resources (because of shading by trees). Hence the scarcity and low quality of graminaceous resource in forest gaps result in decrease of species richness of mammals (Prins and Olff 1998).

In the case of plants, available evidence suggests that a decrease in species richness with resource enrichment is most common, or at least that a humped curve of species richness will be found if the whole productivity range is examined (Begon et al. 1990). Our results confirmed the decrease of species richness of plants with increase of average NDVI (figure 3b). However, since only two districts were analyzed at a time, a humped curve of species richness could not be realized. Why does enhanced productivity tend to reduce the species richness of plants? One possible explanation could be that as nutrients increase, light becomes more and more of a problem for competing plants (Newman 1973); thus higher productivity is associated with increasingly intense competition for light (Huston 1994). However, at very low levels of productivity, diversity increases with increasing productivity, producing a unimodal 'hump-shaped' curve (Huston 1979). The relationship between interannually integrated average NDVI and bird species richness was positive and moderately strong (table 1). This implies that higher average NDVI results in higher species richness (figure 3d).

Why does high productivity tend to increase species richness of birds? One possible explanation could be that in natural habitats bird populations are positively correlated with the amount of woody vegetation (Pomeroy and Dranzoa 1997). Since there is increased production of woody species in highly productive ecosystems (Prins and Olff 1998), bird species richness too increases with woody vegetation (Pomeroy and Dranzoa 1997). Moreover, many species of landbirds use trees as a source of food, or for nesting or as a perch and many waterbirds also nest or perch in trees. In non-forested areas too, the numbers of bird species increase in proportion to the amounts of woody vegetation, that is, trees and shrubs. However, by far the greatest bulk of woody vegetation is to be found in forests, which in the tropics are extraordinarily rich in insect species. These in turn support a rich diversity of birds, almost all of them breeding in the forest (Lewis and Pomeroy 1989).

Species richness of mammals and plants exhibited a positive correlation (table 1) with indices of habitat heterogeneity (standard deviation of maximum NDVI and coefficient of variation). This confirms that highly variable areas are endowed with high number of species. In addition, the positive relationships provide evidence that the standard deviation of maximum NDVI and coefficient of variation are related to variability of vegetation cover, which is in agreement with the spatial heterogeneity hypothesis of species richness (Walker et al. 1992). On the other hand, bird species richness showed significant negative association with NDVI parameters (viz. standard deviation of maximum NDVI and coefficient of variation). In this case, most likely areas with rather low average NDVI and relatively high standard deviation and high coefficient of variation represent unstable areas (arid environments) with erratic rainfall, it is the combination of amount and reliability of rainfall that limits the growth of woody species. Since bird species diversity is correlated with the amount of woody vegetation in natural habitats (Pomeroy and Dranzoa 1997), the scarcity of woody species reduces bird species richness.

\section{CONCLUSION}

The study reveals the relationship between interannually integrated NDVI parameters (viz. average, standard deviation and coefficient of variation) and species richness of birds, mammals and plants in the tropics. This indicates that NDVI represents the integration of climatic variables at a given location and time (Anyamba and Eastman 1996) influencing patterns of species richness. However, the ability to estimate environmental factors from remotely sensed data with reliability is of considerable importance if we are to manage natural resources, and preserve biological diversity. 
Our work has demonstrated that remote sensing technology is a promising means for estimating relevant environmental factors responsible for geographical variability of species richness and can be used to distinguish critical places where a maximum number of species occur.

\section{ACKNOWLEDGEMENT}

We are grateful to the Netherlands Ministry of Development Co-operation and Ministry of Education for funding the research under the Netherlands Fellowship Programme. The authors acknowledged USAID/FEWS Project for providing valuable NDVI time series images through the Internet. Appreciation goes to H. Mwendwa, Director of Department Resource Surveys and Remote Sensing, Ministry of Environment, Kenya (DRSRS) for providing plant and animal species data.

\section{REFERENCES}

ADDS, 1999. Africa Data Dissemination Service, EROS Data Center, U.S. Geological Survey Sioux Falls South Dakota, US 57198. http://edcsnw4.cr.usgs.gov/adds/adds.html\#adds overview anchor (24 Feb. 2000)

Anyamba, A. and Eastman, J.R., 1996. Interannual variability of NDVI over Africa and its relation to El Nino/Southern Oscillation. International Journal of Remote Sensing, 17(13), pp.2533-2548.

Bannari, A., Morin, D. and Bonn, F., 1995. A Review of vegetation indices. Remote Sensing Reviews, 13, pp. 95-120.

Begon, M., Harper, J.L., Townsend, C.R., 1990. Ecology: Individuals, populations and Communities ( $2^{\text {nd }}$ edit). Blackwell Scientific Publications, Cambridge, pp. 816-844.

Box, E.O., Holben, B.N., and Kalb, V., 1989. Accuracy of the AVHHRR Vegetation Index as a predictor of biomass, primary productivity and net $\mathrm{CO} 2$ flux. Vegetatio, 80, pp. 71-89.

Brown, J.H., 1988. Species diversity. In: Analytical Biogeography: An integrated approach to the study of animal and plant distributions, edited by A.A. Myers and P.S. Giller, Chapman and Hall, pp. 57-89.

Connell, J.H., and Orias, E., 1964. The ecological regulation of species diversity. America Naturalist, 98, pp. $399-414$.

Currie, D.J., 1991. Energy and Large-scale Patterns of Animal- and Plant- Species richness. The American Naturalist, 137(1), pp. 27- 49.

Diamond, J., 1988. Factors controlling species diversity: Overview and synthesis. Annals of the Missouri botanical Garden, $75, \mathrm{pp} .117-129$.

Efron, B., and Tibshirani, R.J., 1998. An introduction to the Bootstrap. Monographs on Statistics and Applied probability 57, Chapman \& Hall/CRC, London.

Griffin, G.F., and Friedal, M.H., 1985. Discontinous change in central Australia: some major implications of ecological events for land management. Journal of Arid Environment, 9, pp. 63- 82.

Grime, J.P., 1979. Plant strategies and vegetation processes. John Wiley \& Sons, New York.

Hart, T.B., Hart, J.A., and Murphy, P.G., 1989. Monodominant and species-rich forests of the humid tropics: causes for their co-occurrence. America Naturalist, 133, pp. 613- 633.

Henricksen, B.L., 1986. Reflections on drought: Ethiopia 1983-1984. International Journal of Remote Sensing, 7(11), pp. 1447-1451.

Hobbs, R. J., 1990. Remote sensing of spatial and temporal dynamics of vegetation. In: Remote Sensing of iosphere Functioning. Ecological Studies 79, edited by, R.J. Hobbs and H.A. Mooney, Springer- Verlag, New York, pp.203-219.

Holben, B.N., 1986. Characteristics of maximum-value composite images for temporal AVHRR data. International Journal of Remote Sensing, 7(11), pp.1435-1445.

Huete, A.R., Jackson, R.D., and Post, D.F., 1985. Spectral response of a plant canopy with different soil backgrounds. Remote Sensing of Environment, 17, pp. 37-53.

Huston, A. H., 1994. Biological Diversity. The coexistence of species on changing landscapes. Cambridge University Press, Cambridge.

Huston, M., 1979. A general hypothesis of species diversity. The American Naturalist, 113(1), pp. 81-101.

Lewis, A. and Pomeroy, D., 1989. A bird atlas of Kenya. A.A.Balkema, Rotterdam.

Mcintyre, G.A., 1978. Statistical aspects of vegetation sampling. In: Measurement of grassland vegetation and animal production, edited by L.'t Mannetje, Commonwealth Agricultural Bureax, England, pp.8-21.

Malingreau, J.P., 1989. The vegetation index and the study of vegetation dynamics. In: Applications of Remote Sensing to Agrometerology, F. Toselli (ed.), Kluwer Academic, Brussels, pp. 285-303.

Newman, E.I., 1973. Competition and diversity in herbaceous vegetation. Nature, 244, pp.310-311.

Norton- Griffiths, M., 1978. Counting animals. In Grimsdell, J.J.R., ed. Counting Animals, 2nd edn. Handbook no. 1. Africa Wildlife Leadership Foundation, Nairobi, Kenya. 
Pomeroy, D., and Dranzoa, C., 1997. Methods of studying the distribution, diversity and abundance of birds in East Africa-

some quantitative approaches. African Journal of Ecology, 35, pp.110-123.

Prince, S. D., 1991. Satellite remote sensing of primary production: comparison of results for Sahelian grasslands 19811988. International Journal of Remote Sensing, 12(6), pp.1301-1311.

Prins, H. H. T. and Olff, H., 1998. Species-Richness of African grazer assemblages: Towards a functional explanation. Dynamics of Tropical Communities, edited by, D. M. Newbery, H. H. T. Prins and N. D. Brown, Blackwell Science, Oxford, pp. 449-490.

Richard, Y., and Poccard, I., 1998. A statistical study of NDVI sensitivity to seasonal and interannual rainfall variations in Southern Africa. International Journal of Remote Sensing, 19(15), pp. 2907- 2920.

Rosenzweig, M. L. and Abramsky, Z., 1993. How are diversity and productivity related? In: Species diversity in ecological communities. Historical and geographical perspectives, edited by, R.E. Ricklefs and D. Schluter, University of Chicago Press, Chicago, pp. 52-65.

Sanders, H.L., and Hessler, R.R., 1969. Ecology of the deep sea benthos. Science, 163, pp.1419-24.

Sellers, P.J., 1985. Canopy reflectance, Photosynthesis and transpiration. International Journal of Remote Sensing, $6: 1335$. Tucker, C. J. and Sellers, P. J., 1986. Satellite remote sensing of primary production. International Journal of Remote Sensing, 7(11), pp. 1133-1135.

Walker, R. E., Stoms, D. M., Etes, J.E., and Cayocca, K.D., 1992, Relationships between biological diversity and multitemporal vegetation index data in California. Technical Papers of the 1992 Annual Meeting of ASPRS/ACSM held in Albuquerque, New Mexico, 3-7 March, 1992, (Bethesda, MD: American Society for Photogrammetry and Remote Sensing). pp. 562-571.

Whittaker, R.H., and Niering, W.A., 1965. Vegetation of the Santa Catalina Mountains, Arizona. (II) A gradient analysis of the south slope. Ecology, 46, pp. 429-52. 